Natural Hazards and Earth System Sciences, 5, 345-355, 2005

SRef-ID: 1684-9981/nhess/2005-5-345

European Geosciences Union

(C) 2005 Author(s). This work is licensed

under a Creative Commons License.

\title{
Public perception of flood risks, flood forecasting and mitigation
}

\author{
M. Brilly ${ }^{1}$ and M. Polic ${ }^{2}$ \\ ${ }^{1}$ University of Ljubljana, Faculty of Civil and Geodetic Engineering, Jamova 2, 1000 Ljubljana, Slovenia \\ ${ }^{1}$ University of Ljubljana, Faculty of Arts, Department of Psychology, Askerceva 2, SI-1000 Ljubljana, Slovenia
}

Received: 27 September 2004 - Revised: 21 December 2004 - Accepted: 15 March 2005 - Published: 18 April 2005

\begin{abstract}
A multidisciplinary and integrated approach to the flood mitigation decision making process should provide the best response of society in a flood hazard situation including preparation works and post hazard mitigation. In Slovenia, there is a great lack of data on social aspects and public response to flood mitigation measures and information management. In this paper, two studies of flood perception in the Slovenian town Celje are represented. During its history, Celje was often exposed to floods, the most recent serious floods being in 1990 and in 1998, with a hundred and fifty return period and more than ten year return period, respectively. Two surveys were conducted in 1997 and 2003, with 157 participants from different areas of the town in the first, and 208 in the second study, aiming at finding the general attitude toward the floods. The surveys revealed that floods present a serious threat in the eyes of the inhabitants, and that the perception of threat depends, to a certain degree, on the place of residence. The surveys also highlighted, among the other measures, solidarity and the importance of insurance against floods.
\end{abstract}

\section{Introduction}

New technologies have tremendously increased the possibilities of weather and hydrological forecasts. Meteorological and hydrological models can provide forecasts several days before a flood event starts due to high precipitation (Brilly, 1992, 2000). Satellites and radar enable the monitoring of precipitation systems, and the automated rain and stream gauges provide information in a timely manner (Kelsch et al., 2001). However, the numbers of flood victims are still high, mainly due to the lack of knowledge and inadequate behaviour of the people involved in a flood event. The hydrometeorology of floods in the headwater part of the watershed is very complex and remains shrouded in uncertainty.

Correspondence to: M. Brilly

(mbrilly@fgg.uni-lj.si)
Yet, even given this, these more technical aspects are better recognised compared to what is known about people's behaviour (Montz and Gruntfest, 2002).

Changes in the societal environment and the constant increasing of flood warning performance have many implications for people's behaviour and attitudes as well as for decreasing the number of victims in developed countries. In society there is an increase in vulnerability and a decrease in the tolerance of flood risk. At the same time technology has developed a longer time lag for an appropriate forecast of floods. Various groups involved in the warning task should co-operate in all aspects of community safety, and warnings should become a community's right rather than an agency's discretion (Gruntfest and Handmer, 2001).

Absolute safety against flooding cannot be achieved, but people prefer to feel safe. They like to pay the lowest cost, while asking for satisfying solutions. The best answer to flood management lies in an integrated approach and joint actions. First, we need a clear understanding about the processes and magnitudes of the hydrologic cycle and vulnerability related to the people who might be affected in the process. Flood risk mitigation is a long-term and permanent action. For an integration that includes space, time, and policy activities, it should also include all actors: the inhabitants, local and provincial authorities, the government and Intergovernmental River Management Associations (Brilly, 2001). There is a lack of knowledge about hazards in general, but even more, we need greater knowledge of the vulnerability, which includes the reaction of people involved in - and the time lag between - warning and implementation.

\section{People and floods}

Floods are considered as the most studied natural disasters. The studies about floods were the first to include the psychological aspects accompanying flood events. The beginning of the research on perception of floods is connected to the names of the geographers White and Burton (after McAn- 
Table 1. Multiple regression analysis on the preferred period of advanced warning in 1997 and in 2003.

\begin{tabular}{ccccccc}
\hline YEAR & $R$ & Adj. $R^{2}$ & Gender & Education & No. of reported floods & Trust in forecast \\
\hline 1997 & 0.325 & 0.09 & 0.206 & -0.18 & 0.185 & \\
2003 & 0.45 & 0.20 & & & & 0.45 \\
\hline
\end{tabular}

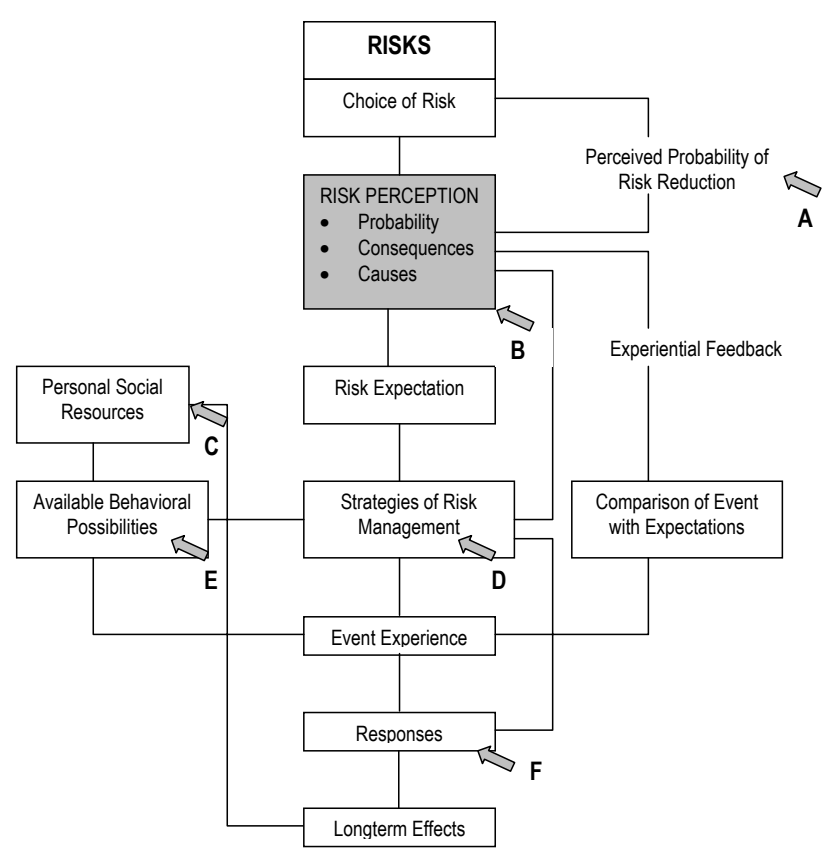

Fig. 1. Intervening strategies in public management of risks (Green et al., 1990).

drew, 1993). Kates (1976) found out that people who had experience with floods were more likely to expect that they would reappear, and consequently they act protectively. The majority of inhabitants living in areas where floods or other disasters are frequent are prone toward an underestimation of danger (Gardner and Stern, 1996). Many believe that floods would not re-occur several years after the last appearance, even during their life times. Whyte (1986) distinguished three groups of factors influencing amplification of the perceived risk:

- Personal characteristics: lower education, gender, age, being a parent, anxiety, etc.

- Situational factors: event is not under control of the individual, nonvoluntary exposure, recent dangerous event, threat to children, inadequate resources, lack of confidence in the authorities, contradictory scientific opinions, great media attention, etc.

- Risk charactericstics: immediate threat, direct health consequences, low probability of danger, unknown new danger, fear arousing danger, a lot of mortal cases, etc.

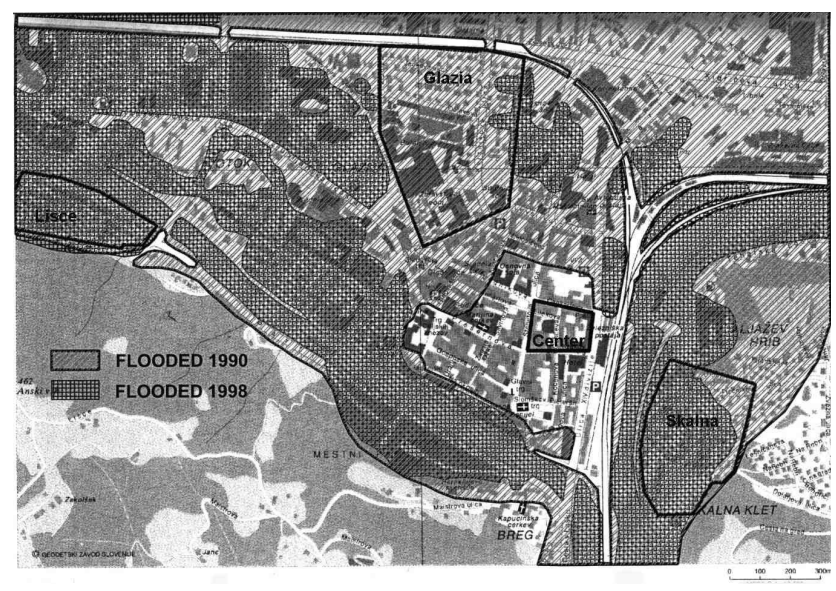

Fig. 2. Areas of Celje flooded in 1990 and 1998.

In a study conducted by Polic et al. (1991), more than a half of the interviewees after the spring floods denied the possibility of flood reappearance during the same year, although autumn floods are quite frequent in Slovenia. Indeed, floods reappeared in autumn that year. In another study, Polic et al. (1998) established that the inhabitants of inundated areas felt more threatened by floods than people coming from areas where floods are non-existent or rare. Kunreuther (after Gardner and Stern, 1996) stated that many house owners in flood and earthquake-prone areas in USA were not insured against these dangers, although insurance was rather inexpensive and the government supported it in $90 \%$.

Researches (Ittelson et al., 1974) have constantly reported the differences in estimations by experts and lay people. Quite often lay people tend to exclude themselves from the pattern of risk, or otherwise completely deny the danger. They would act only when the probability of danger overcomes the uncertainty or when the size of the disaster causes crisis responses.

Green et al. (1990) studied the planning of countermeasures during the floods. The purpose of acting was to decrease the long-term consequences of events, either by decreasing the size of impact or by supporting the mitigation of consequences. The authors believe that because of this we should be able to recognise the points of intervention, in which we could decrease the frequency and size of floods (Fig. 1).

The model of Green et al. (1991) is built on the presumption that beliefs influence the appearance of expectations about future events, also floods, as well as the explanation 
of events and actions, which suit the circumstances. These expectations limit not only the public responses but also the responses of protection and rescue services. Fear of panic often causes delay in warnings by the responsible authorities, which often occurs during floods. The model indicates that we could contribute towards greater safety by influencing the perception of risk.

Green et al. (1991) in another study affirmed that lay people consider the possibility of floods as a causal process, while experts treated it as a random event. If a flood appears, lay people explain it as a result of an error, but if for some time there are no floods, this means that people had actually something to prevent them. People who had experienced floods usually develop a causal model of flooding, by which they try to forecast future floods. Thus, in areas with tidal floods people typically buy tidal tables. When there is a storm during the winter they look in the tables to check for high tide. Only if both factors were present they would believe that a flood would occur. The experience of flood also gave the affected people a feeling that in future they would be able to cope with the situation. After the flood they try to do something to decrease the future threats. Their concerns are connected with the estimation of the flood intensity. They became angry if they believed that some preventive actions could be undertaken, but were not.

\section{Study area}

The focus of this study is people's perception of flood risks in the Slovenian town of Celje (around 41300 inhabitants) and their attitudes about flood prevention and flood management. The study is not connected to any concrete flood, but appraises the general perception of floods and related events (e.g. warnings, mitigation measures). The city is situated on the confluence of the Savinja River, main tributary of the Sava River in Slovenia, and the Voglajna River (Fig. 2). The watershed of the Savinja River upstream of Celje has an area of $1192 \mathrm{~km}^{2}$, and the Voglajna River in the confluence has an area of $413 \mathrm{~km}^{2}$. As early as in Roman times, the Savinja and its tributary were known to inundate the surrounding areas. There is a flood mark of water level dated September 1672 on the tablet built into the tower wall. The tablet is a monument of cultural heritage situated in the Public Park and well known to inhabitants.

The water station in Celje was constructed in 1870. Floods occurred several times during the last century: The worst floods that occurred in the last century were in 1933, 1954, 1980, and 1990 (Fig. 3). The last serious flood was in 1998, when part of the town was also additionally flooded by extremely high water of the Voglajna River (Fig. 2). The most serious flood in the last century was on the Savinja River on 1 November 1990, with a return period of one hundred and fifty years (Fig. 3). The hydrological forecast predicted a serious flood event the day before. Large-scale bank erosion removed riparian vegetation, which jammed bridges and caused an additional rise of the water level. The inner area of

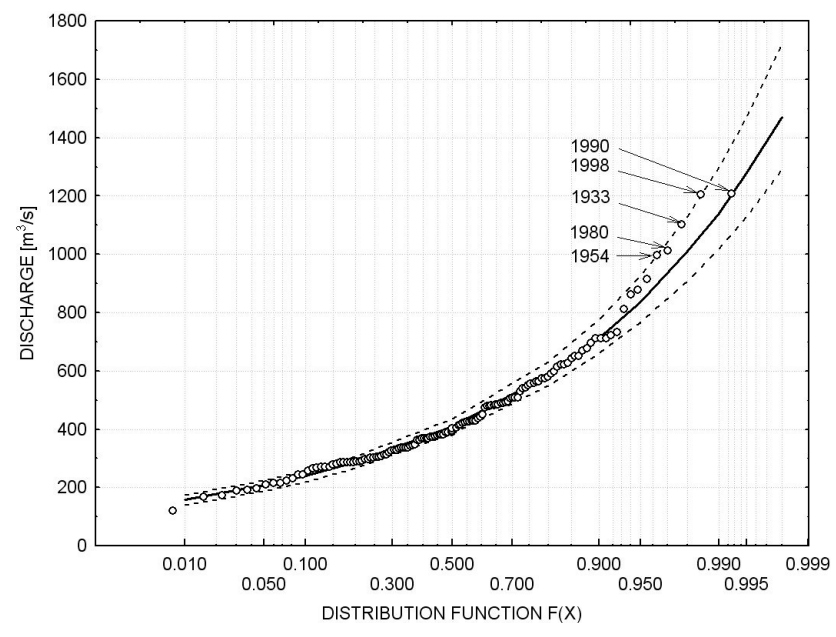

Fig. 3. Flood frequency curve of the Savinja River at the water station in Celje.

the town was flooded and only the Old City and railway were spared. The flood level in the most serious flood of 1990 was about one metre below the medieval mark.

During the flood on 5 November 1998 the discharge in the Savinja River reached over the 10 -year return period, and at the same time the discharge in the Voglajna River exceeded the 50-year return period and the city was seriously flooded again (Polajnar 1999).

Regulation of the river channel started as early as in the 19th century for protection of the railway but is still not completed for flood protection of the city area. During the 20th century, people started to settle in the areas that were prone to floods, and several flood protection works were developed also after the 1954 flood; the river was regulated and the stream cross-section increased, and levees were also built on both sides of the stream. The urbanised areas were protected against 50-100-return period floods, but the outlets from the sewerage system remained open, and floods could flow into the protected urbanised areas of the town. During the 1990 flood events, the water flowed into the town through the outlet of sewerage system. Also, erosion released trees from the riverbank, thus blocking the bridges. The in-stream water level increased and the nearby levees were overflowed and destroyed. After the 1990 flood the country was undergoing social and economical transitions, so there were not enough funds for public works and only minor reparation works were realised. In the 1998 flood the sewage outlets were not protected and bridges were blocked on the Voglajna River. The Savinja River flooded through sewage system and the Voglajna River overflowed the levees.

There were two victims in the accidents connected with the flood in 1990, and two victims in the 1998 flood, but outside the municipal area. The floods produced great material damage in the town. The direct damage in the town area was $110 \times 10^{6}$ EURO in 1990 and $10 \times 10^{6}$ EURO in 1998 , respectively (Adamic, 1991). The damage value in 1990 is loaded by the unrealistic currency exchange, however the damage in 
1990 was several times higher than in the 1998 flood.

One of the studied factors was the influence of the place of residence or, more precisely, the proneness of a particular place toward floods, and inhabitants ' perception and preparation for countermeasures. Inhabitants of both inundated and non-inundated areas participated in the study. Participants lived in the areas shown in Fig. 2. The study investigated the perception of the people at risk and their general situation in the scope of floods (e.g. their probability, characteristics, countermeasures, warnings). Did they feel safe due to accelerated regulation measures during that time, bearing in mind that the Celje region is still flood-prone today? We must take into account that during the last 50 years the inhabitants of Celje suffered from serious floods four times and in recent times in 1990 and 1998 (Fig. 3). The area was flooded up to three metres high.

The Central area of the town is medieval and is situated outside the flooded area. Its inhabitants are not under immediate threat of floods, or perhaps to a certain degree only indirectly because of the neighbouring flooded areas. Only the underground floors of buildings could be flooded in this area by sewage outflow. People live manly in multi-storey houses.

The Glazija, the area Northwest of the Centre, has been settled in the past forty years with multi-storey houses. The urban area is half a kilometre away from the riverbed and levees. The inhabitants surprisingly suffered from a flood in 1990 , and partly in 1998 , when it was partly flooded by the inflow through the sewerage system. However, floods do not haunt the area frequently and the inhabitants are not daily affected by the Savinja River water regime.

The Lisce, area located on the west of the Centre, is a flood-prone area and protected by levees. The frequently flooded area has been settled during the last 30-40 years with one-storey houses. Its inhabitants are fairly familiar with the Savinja River, as they are able to observe the river through their windows. They are also familiar with the insufficient flood protection of the area because the plan of flood defence structures was presented and discussed in public, but it was not completed. After 1990 the flood protection was improved, but the construction works were not completed and the area was flooded again in 1998.

The Skalna is an often-flooded area, which was additionally included in the 2003 survey. Levees and a pumping station for inland drainage water during flood events protect the area, situated east of the Centre. The area has been settled in the past forty years on a previously inundated surface with one-storey houses. It was flooded also in 1990, and protection works - including construction of a pumping station for inland waters - were carried out afterwards. Although the area was considered by the responsible authorities as being safe against floods of the Savinja water, it was nevertheless seriously flooded in 1998 by high discharge of the Voglajna River, which was redirected by a jammed bridge over the levees in the protected area. The inhabitants are familiar with the river. The area was flooded in 1990, and protection works, including construction of a pumping station for inland waters, were reconstructed after 1990. The area is considered safe against floods of the Savinja water, however it was seriously flooded in 1998, by an unexpectedly high discharge of the Voglajna River, which was suddenly redirected over the road in the protected area by jammed bridge.

\section{Method}

Two surveys were undertaken in the town of Celje. The first one was carried out in 1997, seven years after the flood in 1990. The survey was a contribution to the EU project "FLOODAWARE", focusing on the mitigation measures and flood defence strategies (Polic et al., 1998). A second survey in 2003, five years after the flood in 1998, was carried out as a contribution to the EU project European Flood Forecasting System (EFFS) and it was more oriented towards information management and forecasting. The surveys were aimed at general attitudes toward floods and not special experiences after the actual flood; however we presume that inhabitants are experienced with past flood events, and were therefore not responding out of the stress caused by a recent flood event.

\subsection{Participants}

In 1997, a total of 157 people participated in the study, while in 2003 there were 208 participants. In 1997 there were 74 males and 83 females, aged 44.13 years on average ( $\mathrm{SD}=15.98$; min. 17 years and max. 77 years), the prevailing educational level was secondary school. In 2003, there were 92 males and 112 females (two missing values), aged 51.46 years on average $(\mathrm{SD}=19.10$; min. 17 years and max. 101 years, the prevailing educational level being secondary $(47 \%)$ and higher $(31.2 \%)$. In both studies the respondents were equally distributed around all three/four areas, which means that about fifty participants were included in the surveys from each area. Three areas, i.e. the Centre, Glazija and Lisce, were included in the first survey in 1997, and the area of Skalna was added in the 2003 survey. In both cases, the survey was carried out among the randomly selected inhabitants. Regarding the sizes of the included areas, the majority of households were included in the surveys.

\subsection{Survey}

In both studies, special questionnaires with 18 (in 1997) and 22 (in 2003) mainly close-type questions were used, asking about demography, perceived frequency and characteristics of floods, concerns about them, opinions about countermeasures and responsibilities, and certain warning characteristics (e.g. timing, credibility). The respondents were asked to mark the areas of Celje threatened by floods on a map. The questions in the second questionnaire somewhat differ from those in the first. Some questions were more precisely phrased; others, which were indiscriminate in the first inquiry, were left out. Nevertheless, the core part of both questionnaires still allowed several comparisons. 
Specially trained students conducted the questionnaires personally in the participants' homes in 1997 and 2003. About 50 inhabitants were selected randomly on each area (Fig. 2). In both cases, the questioning was carried out during the periods without floods or imminent flood danger, i.e. seven to five years after the floods. The difference in average age of participants between both surveys is same rate as the difference in time of the survey.

\section{Results and discussion}

Experiences of inhabitants with floods were different from area to area. In both surveys, the differences in answers by participants from different areas were statistically significant. The town was two times seriously flooded in the period of the past ten years, which the participants remembered correctly, (Fig. 4). However, their expectations and concerns differed. The inhabitants with an unexpected experience of flooding (the Glazija and Skalna areas) expressed more concerns than did the inhabitants in the Lisce area, the area most exposed to flooding. On the basis of these answers it was possible to examine the influence of threat on the perception of risk and attitudes toward different aspects of floods (Fig. 4).

It is evident that the experiences with floods influence the perception of probability of future floods and concern in that respect. In 1997, the estimations of flood probability were lower by inhabitants from safer areas and highest by the inhabitants of the Lisce area, while the situation in 2003 changed. This shift is hard to explain, but it may be ascribed to the different phrasing of the questions (open questions in the first survey and closed in the second) and possible differences in recent flood experiences. On average, in 1997 the inhabitants believed that in the next 10 years there would be 1.95 floods in Celje (range from 0 to 10 floods).

In both cases, it is evident that the participants from previously inundated areas are more concerned about possible future floods than elsewhere. In both replications, the differences were statistically significant, though in 1997 they were rather small. In 1997, all inhabitants were concerned with possible floods. Multiple regression analysis $(R=0.55)$ revealed that at least $29 \%$ of variability could be explained by the fear of floods $(\beta=0.42)$, number of previous floods of home ( $\beta=0.16)$ and by the age of respondents $(\beta=0.16)$. Other aspects of floods did not influence their concerns. In 2003 , multiple regression analysis $(R=0.68)$ revealed that at least $44 \%$ of variability of the answer could be explained by the fear of floods $(\beta=0.33)$, estimated number of future floods $(\beta=0.30)$, number of previous floods $(\beta=0.22)$, estimation about the size of floods $(\beta=0.19)$, age $(\beta=0.16)$, confidence in flood forecast $(\beta=0.12)$, and belief that floods are natural phenomena $(\beta=-0.19)$. However, it should be noted that the perceived threat and concern are not always accompanied by proper actions and counter-measures, as they may be inconvenient and demand great adaptation efforts. Concern because of floods was not (or very lowly) correlated with the preparedness to conduct preventive and other coun-

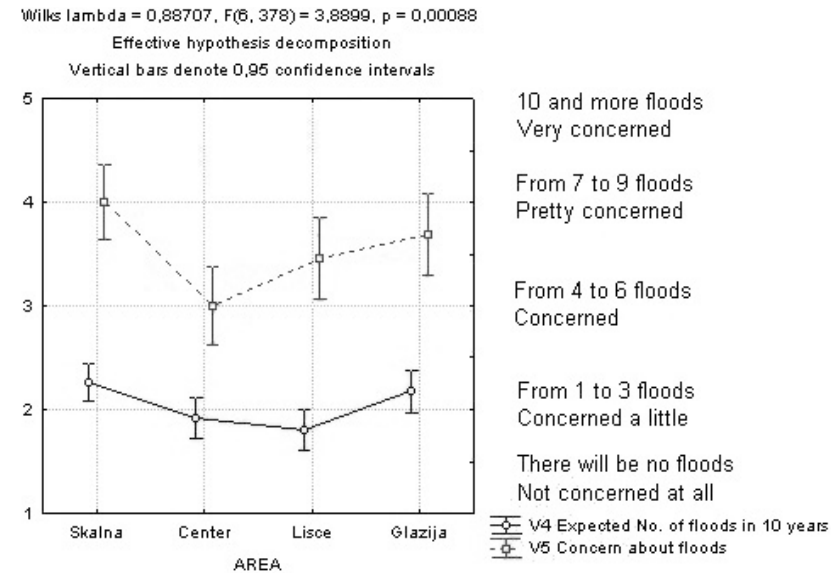

Fig. 4. Perceived possibility of floods and expressed concern about floods in 2003.

termeasures (the highest correlation being 0.14). Two-way analysis of variance revealed that that place of residence has a stronger influence on preparedness to take countermeasures than concern about floods (out of eight significant Fs, five were for place, two for interaction and one for concern). On the cartographic map of Celje, the respondents also had to indicate the areas, which they believed, were threatened by floods. In this way a cognitive map of inundated areas of Celje was designed. Such a map enables an insight into people's perception of flood risk. Nevertheless, cognitive maps could be biased because of different reasons, e.g. specific uses of the environment, current experiences, general knowledge, prejudices, etc. Outlines of the subjective flood risk areas are presented in Figs. 5 and 6.

Participants were able to indicate the threatened areas, and their answers differed depending on the place of residence. This was especially evident in the responses of the participants from the Lisce area, who very clearly indicated their home area and area along the river Savinja as threatened, while other areas were not indicated as threatened to such high degree. Participants from the Centre and Glazija areas indicated wider regions as threatened by floods. At least partially, the cognitive maps reflect the perceived risk of floods.

The indicated areas were somewhat more concentrated in the 2003 survey. Of course, the composite illustration depends on the number of participants from a certain area. Especially salient is the Lisce area, the area along the Savinja and the area of Skalna, which was perceived as threatened mainly by the participants from the Skalna area, and to a lesser degree by others. The participants are sensitive mainly with regard to nearby neighbourhood of up to a few hundred metres distant. Again, people are aware of floods and affected areas. The flood in 1998 might have even strengthened their perception.

Participants were willing to personally undertake the seemingly most relevant measures (e.g. insurance, preparation of water and food), but much less the measures connected with money expenses, and other more demanding 

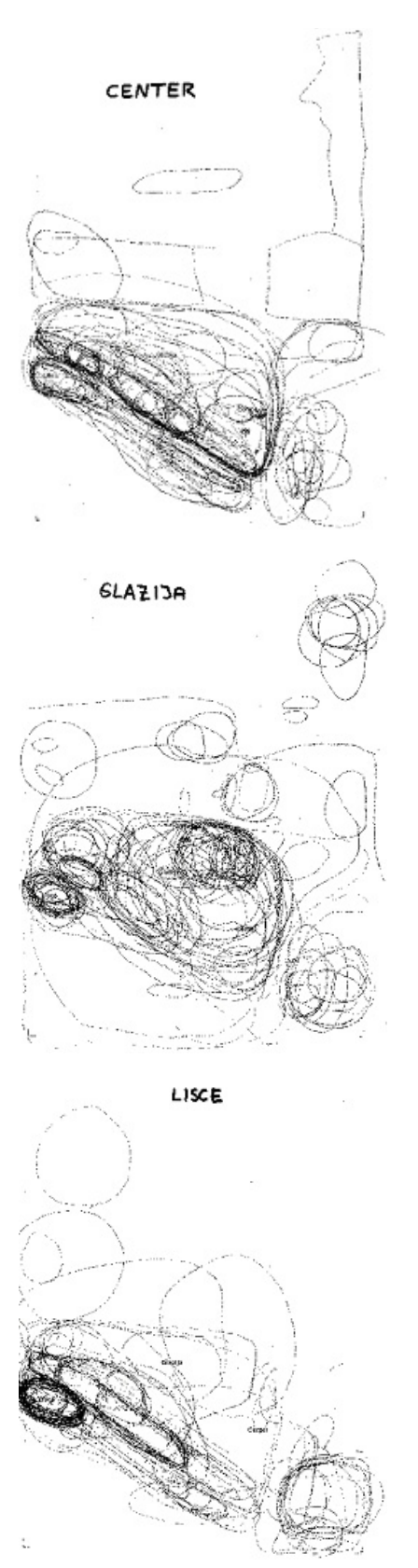

Fig. 5. Map of Celje (threatened parts are indicated with lines) and the aggregated outlines of the areas in risk because of floods, as perceived by the inhabitants of the three parts of the town in 1997.

ones (e.g. affiliation to Civil Protection, moving out). Further development of river regulation structures was not strongly supported. Answers in 1997 and 2003 were similar (Fig. 7), with certain smaller differences, especially the one regarding contribution to solidarity help. Inconvenience seems to be one of the reasons for not taking the necessary precautionary measures. One of the reasons is that the participants were significantly older in 2003 than they were in 1997. This must be taken into account in trying to activate people in protection against floods.
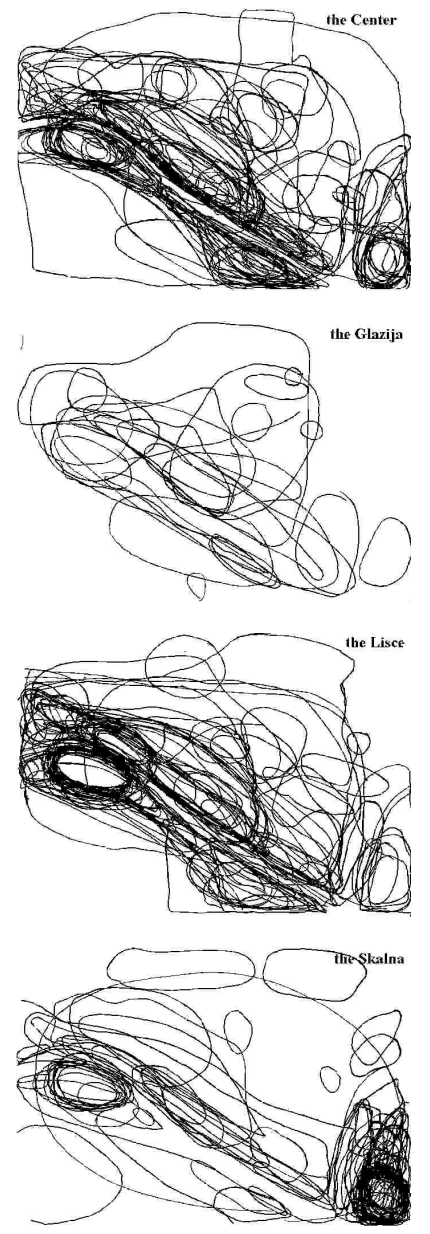

Fig. 6. Lines on the map indicating the parts of Celje threatened by floods, as perceived by the inhabitants of the four parts of the town in 2003.

While before 1990, in different studies (Polic and Ušenicnik, 1989), solidarity was perceived as the primary source of reimbursements after a disaster, with the change of the political system insurance took its leading place. Also in both cases, in 1997 as well as in 2003, insurance appeared as the primary source of reimbursement (Fig. 8). It seems as if people still believed that somebody is obliged to help them. The increase in expectations regarding insurance is perhaps due to the greater number of insured participants $(31.85 \%$ in 1997 and $57.28 \%$ in 2003). Insurance against flood hazard is included in property insurance against fire by special agreement with the insurance company. The country is divided into three zones of flood risk. The costs of flood insurance are relatively high and householders expect some governmental support after the floods, but this support is much smaller and takes some time to be distributed. The insurance companies are more efficient in expenditure (Ferlan and Mikoš, 2002).

Hierarchical clustering analysis showed two groups of sources of reimbursements, while insurance was perceived rather independently (of the two). In one group, there were institutions such as civil society, and in the other group there 


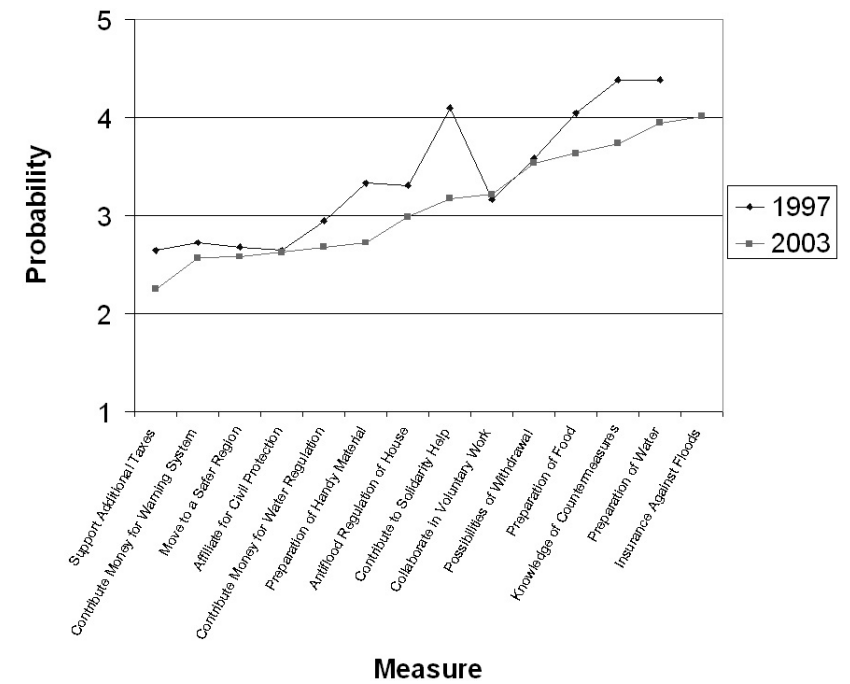

Fig. 7. Willingness to take measures against floods.

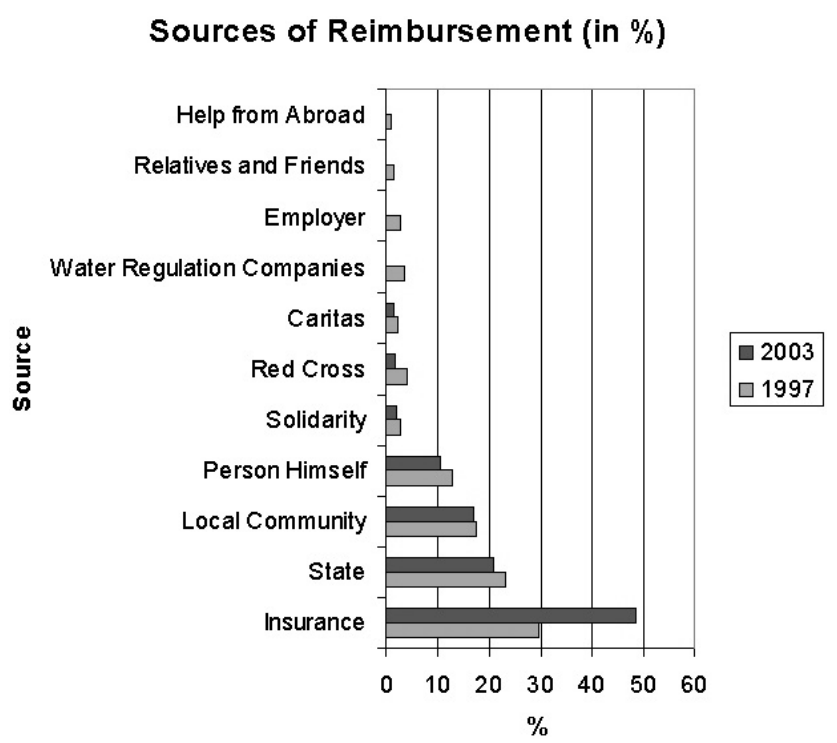

Fig. 8. Sources of funds for reimbursement.

were the state, community and the affected individuals themselves, which were also the main sources regarding the level of their contribution (Fig. 9).

One of the questions was related to the expected period of advanced warnings. In 1997, the majority of participants preferred to be informed about the possible flood at least a few hours before its outbreak. The most frequent answer in all three areas was the one-day warning. In the 2003 enquiry, the average answer was about 12 hours. The time span of the warnings was evidently important, though not the same for all. There were no statistically important differences in the preferred time of advanced warnings between participants from different areas, but women preferred a longer period of advanced warning than men (Fig. 10). And if real risk did not influence the preferred period of advanced warning, it seems as if it was not perceived as an important factor in coping with floods.

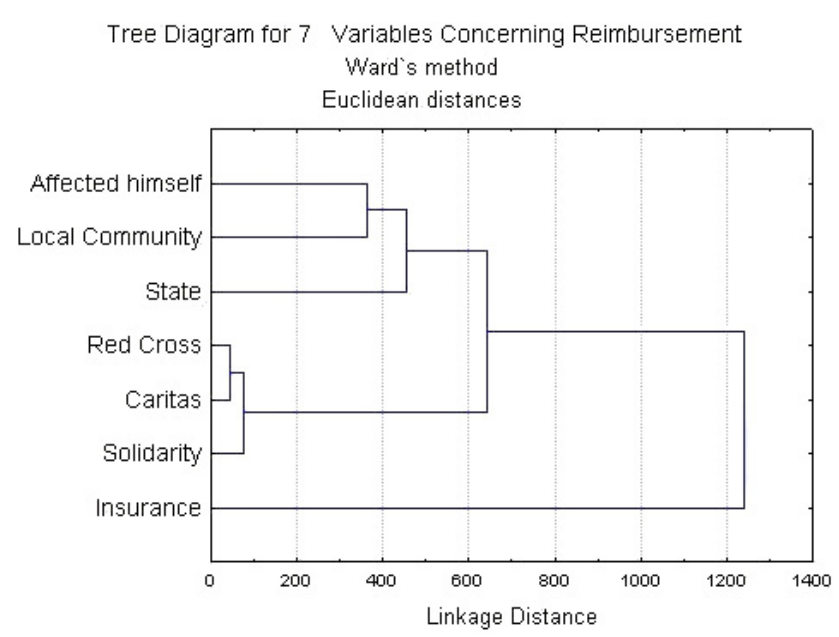

Fig. 9. Hierarchical clustering analysis of sources of reimbursement in 2003.

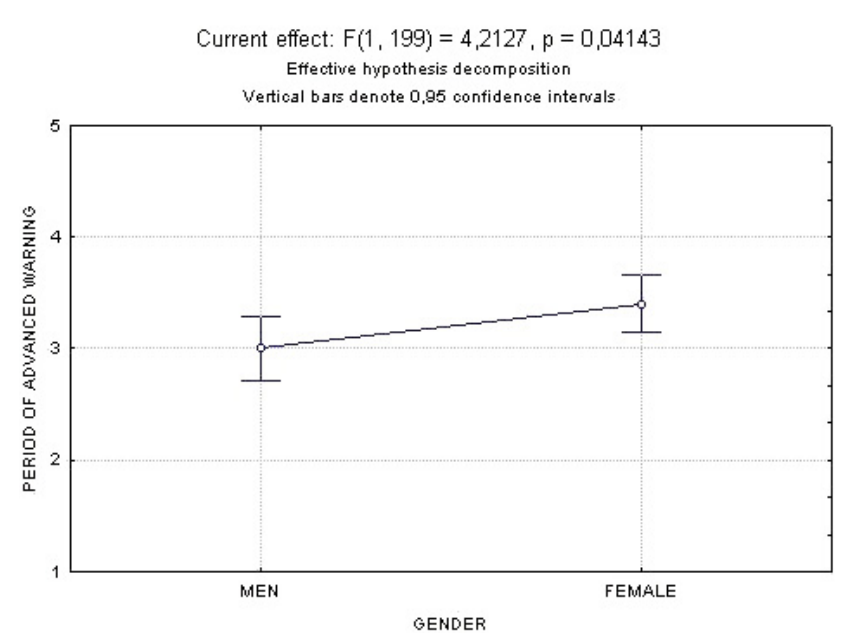

Fig. 10. Gender and the expected period of advanced warning in 2003.

Interestingly enough, neither worries about floods nor reported frequency of them did significantly influence the preferred period of the advanced warning in 2003, while in 1997 there were significant differences in the preferred period of advanced warning and reported number of floods (Fig. 11). Perhaps the recent experiences with warnings or change in the warning system, the consideration of the new area (Skalna), or slightly different phrasing of the questions caused this difference between answers in 1997 and 2003. Also, with the increased reported frequency of floods the variability of the preferred period of warning increased. Otherwise, the general pattern of answers remained pretty similar.

The multiple regression analysis on the preferred period of advanced warning showed statistically significance but a relatively low amount of explained variability of answers regarding the preferred period of warning (Table 1). While in 1997 mainly gender education and the number of reported 

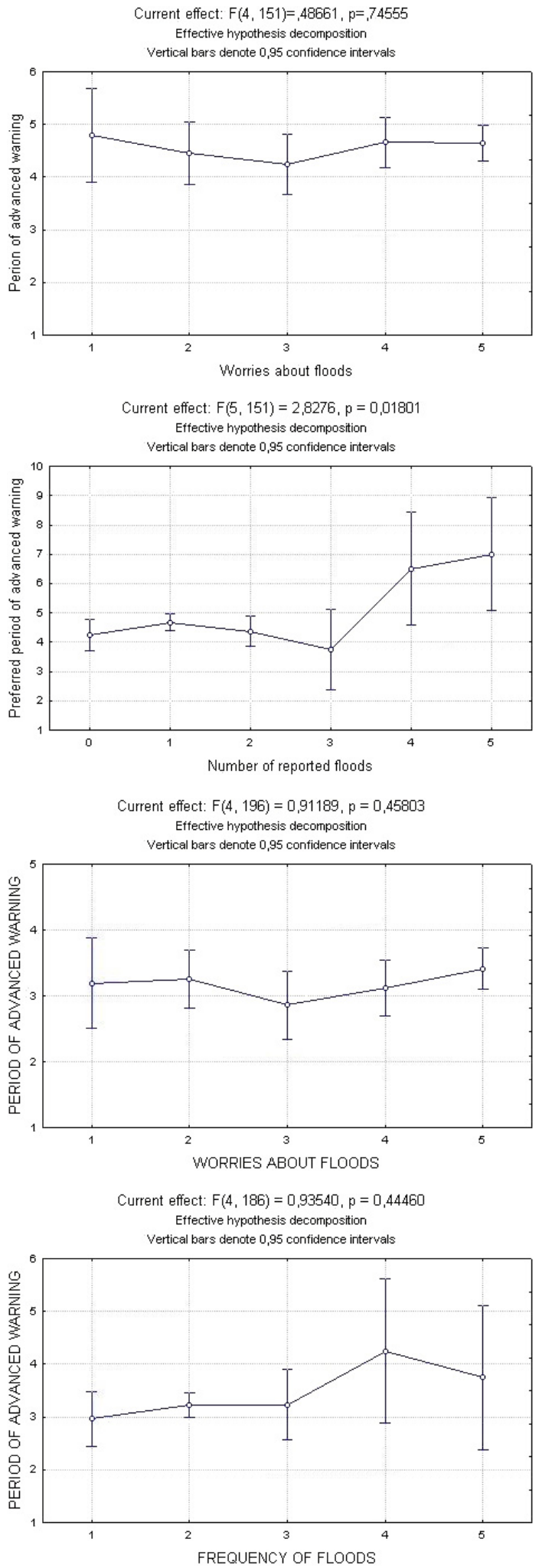

Fig. 11. Worries about flood (a), reported number of flood (b) and the preferred period of advanced warning in 1997 and in 2003 (c) and (d).

floods explained the answer, in 2003 only the trust in flood forecast was significant. It is hard to say whether the reasons

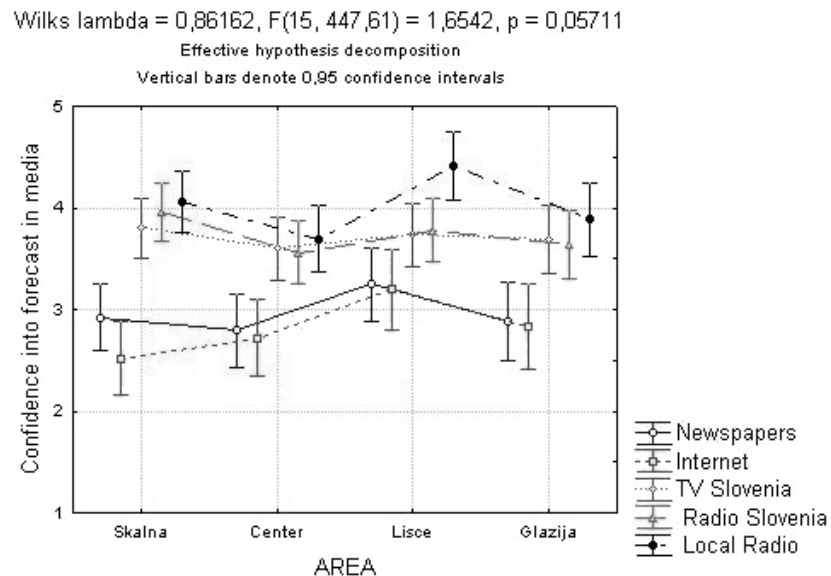

Wilks lambda $=0,96081$, $F(12,476,53)=0,60462, p=0,83884$

Effective hypothesis decomposition Vertical bars denote 0,95 confidence intervals

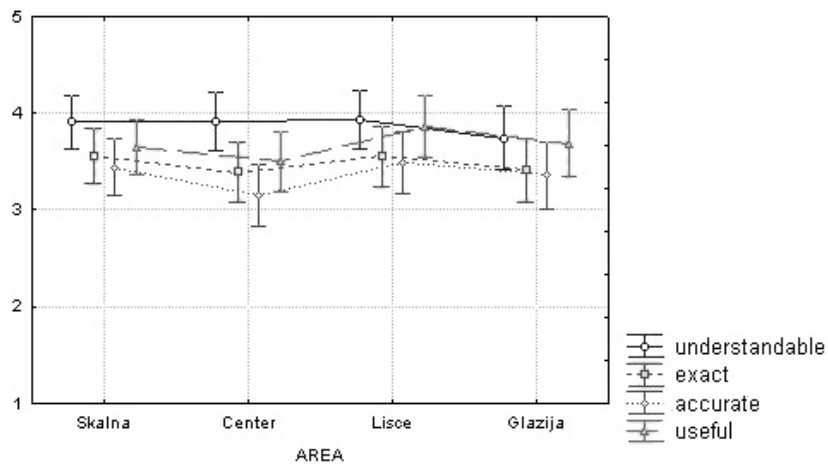

Fig. 12. Credibility of different sources of information about a flood forecast (a), and characteristics of media information about water (b) in 2003, depending on the dwelling area.

for this were the same as mentioned earlier. Multiple $R$ coefficients were statistically significant and only variables with statistically significant $\beta$ s were included in the analysis. The analysis started with the same variables in both cases.

Because floods are usually events caused by weather and hydrological conditions, enlarged time lags in forecasts are possible, and different media could be used for distribution of information. Of course, the printed media are not so useful for simultaneous warnings. Also the possibilities of false alarms or neglect are possible. Nevertheless, the participants in the 2003 study strongly stated that they would like to be informed about a possible flood, even if it would not be certain that the flood would happen. In Slovenia, the threatened population is usually warned by mass media (radio, TV), either local or on the state level, depending on the range of the event. Regarding floods relevant messages are given as a part of the weather forecast. Alarms by sirens serve only to catch the attention of the threatened population in very serious cases when flood is highly probable, and direct them toward relevant media for concrete information or instructions about safety measures (e.g. evacuation). Almost every settlement is equipped with alarm sirens. The experts are afraid 


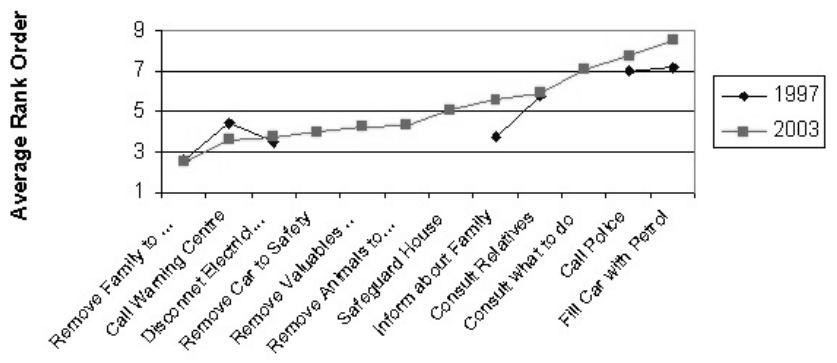

ACTIVITY

Fig. 13. Average rank of activities after hearing about the threat of flood.

of the consequences of false alarms, which have been mainly associated with fire and security related events (Gruntfest and Carsell, 2000). There is no report on the consequences of a false alarm in flood hazards. On the other hand, the consequences of flood events without a public warning may be tragic. Consequences of false alarms in the case of floods are - regarding floods in Slovenia - not so demanding for affected people (going to upper floors or to a nearby higher region). Nevertheless, too many false alarms could result in disregard, but we should also take into account the risk of floods with improper warning. Flood forecasting is loaded with uncertainty from different sources: meteorological and hydrological forecast, unpredictable erosion processes and behaviour of structures. At the other end of the system is the use of the forecasts and, particularly, the warnings that are issued. A time lag exists between the issue of a forecast and the recognition by officials and inhabitants that a serious flood potential exists, so that they release a warning and take the necessary mitigation measures. Time is essential, given the nature of flash floods. In addition, the uncertainty that exists cannot be ignored. A few minutes lost in any part of the warning process can have catastrophic results (Montz and Gruntfest, 2002). Vulnerability of the population at risk increases when people are growing older. They are more unwilling to react quickly and take the necessary mitigation measures (Fig. 7). Hence, timing is of more importance.

From Fig. 12 it is evident that the local radio was the most credible source of information about flood forecasts. This is understandable because a local source is much more timely and direct, being located in the area. Internet is perhaps not so widely used, especially concerning warnings. Thus, radio and TV are much more useful in this sense and were also perceived as such. Certain differences between answers of participants from different areas were evident, and perhaps they reflected the different needs for information as well as relevant experience. Concerning the contents of media messages, they were evaluated as understandable, useful, exact, and accurate. There was no influence of the area on these evaluations. All the participants in 2003 reported that they frequently followed weather forecasts in the media. This answer is understandable, because weather forecasts are a regular part of the highly watched TV and radio news and a

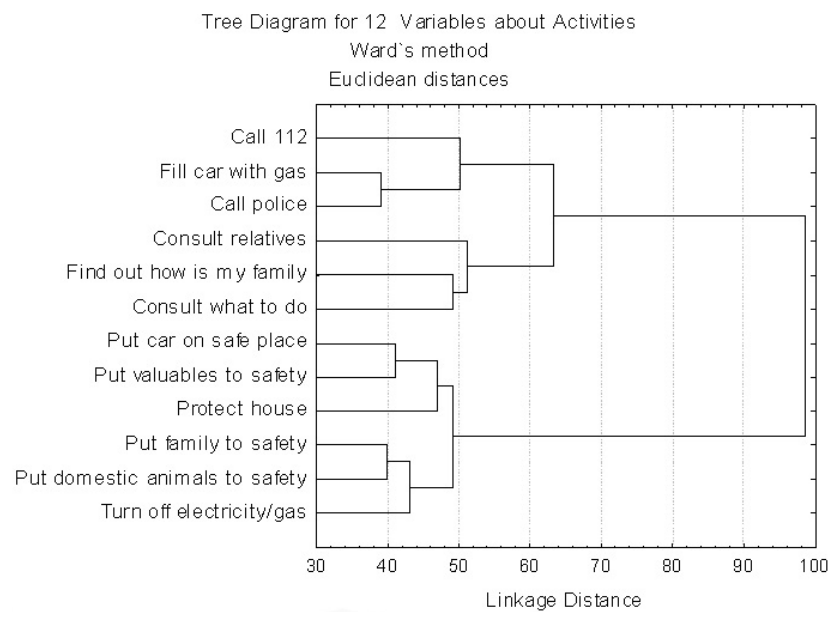

Fig. 14. Hierarchical clustering of activities after the warning against flood in 2003.

widely read newspaper section. At the same time, people are interested in the weather on everyday basis as it affects their daily activities.

Coping with floods is connected with a number of activities, counter-measures and the actors who perform them. What are the most important activities for the respondents of the survey, what would they do first, how would they evaluate different measures and actors?

In both cases the first action would be to take their families to safety and then to call the warning centre, i.e. care for family and need for information are in the first place (Fig. 13). Then some simple and necessary measures would be undertaken. Interestingly, the respondents would as a first step take their family to safety and would only later try to find out about the situation and necessary measures Perhaps the majority believes that the family would be together or that the first step would be to take care of those present. To call the police - once a very popular reaction - has become less common after the establishment of the warning centre.

Two groups of activities are evident: one concerning gaining information and consultation, and the other of different safety-relevant activities (Fig. 14).

Participants differentiate counter-measures in several ways and thus perceive as the most deficient the inadequate river regulation, deficient spatial planning, inadequate state help and deficient community measures (Fig. 15). It seems that they are aware of the real causes of their troubles with flood, i.e. also hydrology experts believe that the regulations were not sufficient and that town planning was deficient.

Notably, the participants evaluated their knowledge of counter-measures between "medium" and "a great deal", which is understandable, regarding the high exposure to floods of the Celje area (Fig. 16). Differences between respondents from different areas were statistically significant. Respondents from the area of Lisce evaluated their knowledge highest, followed by respondents from the Skalna area, while those from the Glazija and Centre areas were about 


\section{Deficiencis in Countermeasures}

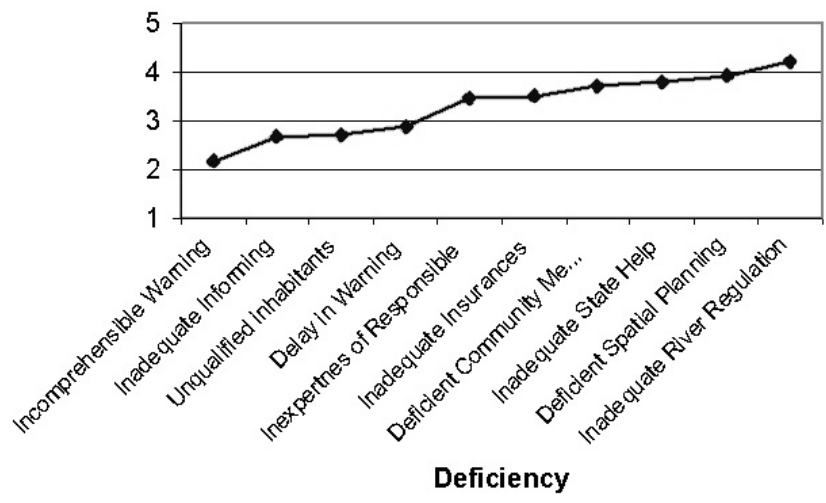

Fig. 15. Opinions about deficiencies in counter-measures in 2003.

the same. It seems that the more frequent the exposure is to floods the higher the estimation of someone's own knowledge is.

\section{Conclusions and discussion}

The study revealed a number of important factors about the interaction between people and floods. Experience with floods influences the perceived threat and concern related to them. As Celje is a flood-prone area, the great awareness of threat and its localisation (as revealed in the cognitive maps) are understandable. It appears that people are more willing to take personally relevant counter-measures rather than costly ones. They are aware of the importance of insurance against floods, and accordingly, the rate of insured individuals has increased. The structural measures including development of river regulation are not so well supported.

The participants like to be well informed and they watch (listen to) local source of information. They can easily move to the upper storey during the flood, take care of food and water supply, but the problem and main objective for civil defence is support for elderly people who have difficulties in moving, and this part of the population is growing.

The flood defence measures should integrate also governmental support for the reinsurance and monitoring of social conditions for proper protection of the most vulnerable part of the population: handicapped, elderly people and children. Information concerning this kind of protection should be provided as soon as possible.

The importance of warnings was clearly highlighted. The local radio was considered as the most important source of information. The information should be as clear and simple as possible with univocal instructions what to do. The problem of false alarms should be considered and their effects mitigated.

On the basis of the study, certain suggestions regarding safety issues emerged:

- need for river monitoring and keeping people informed,

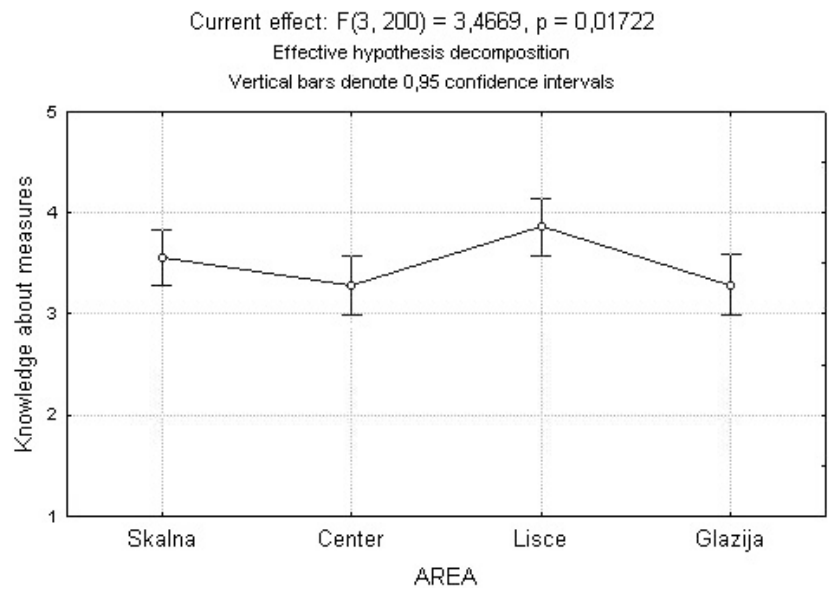

Fig. 16. Self-estimated knowledge about behaviour during floods in 2003.

- importance of insurance,

- proper development of spatial planning and river regulation,

- need for educating and training people about floods and proper reactions during flood events as well as stimulating proper preparation (e.g. insurance).

Flood forecasting has been integrated in the decision-making system for flood protection. The decision-making system was developed in accordance with today's confidence level and lead-time of flood forecasts. Flood forecasting with a lead-time of longer than 1 to 3 days ahead has called for changes in the decision-making procedure. However, an integrated approach to flood protection and rapid technical development requires the additional education of experts and improved public knowledge. Also, the need for further research and the need for co-operation between engineering, natural and social sciences has been clearly identified.

Acknowledgements. The authors wish to thank all the participants involved in the survey and the Celje town council authority for their support and co-operation. The research was funded by the Ministry of Education, Science and Sport of Slovenia for participation in the EU FRIEND project and by the EU EFFS project. The authors wish to thank anonymous reviewers for their valuable comments.

Edited by: F. Castelli

Reviewed by: S. Caragliano and another referee

\section{References}

Adamic, M. O.: Škoda ujme 1990 v Sloveniji, (Flood damage 1990 in Slovenia), Administration of the Republic of Slovenia for Civil Protection and Disaster Relief , Ljubljana, Ujma No. 5, 124-125, 1991.

Brilly, M.: Flood protection on the headwater streams, Floods and Flood Management, Kluwer Academic Publishers, Letcworth, 457-473, 1992. 
Brilly, M.: Application of meteorological mesoscale model ALADIN SI for hydrological forecast, Hydrology days publication, Colorado State University, Fort Collins, 8-20, 2000.

Brilly, M.: The integrated approach to flash flood management, In: Coping with Flash Floods, Edited by: Gruntfest, E. and Handmer, J., Kluwer Academic Publishers, Dordrecht, 103-113, 2001.

Ferlan, M. and Mikoš, M: Naravne nesrece in premoženjsko zavarovalništvo (Natural hazards and property insurance), In: Nesrece in varstvo pred njimi, Edited by: Ušenicnik, B., Administration of the RS for Civil Protection and Disaster Relief, Ljubljana, 545-552, 2002.

Gardner, G. T. and Stern, P. C.: Environmental Problems and Human Behavior, Boston, Allyn and Bacon, 1996.

Green, C. H., Parker, D. J., and Penning-Rowsell, E. C.: Lessons for Hazard Management for United Kingdom Floods, Enfield: Flood Hazard Research Centre Publication No. 177, 1990.

Green, C. H., Tunstall, S. M., and Fordham, M.: The Risks from Flooding: Which Risk and Whose Perception. Enfield: Flood Hazard Research Centre Publication, 1991.

Gruntfest, E. and Carsell, K.: The Warning Process: Toward an Understanding of False Alarms, Department of Geography and Environmental Studies, University of Colorado at Colorado Springs, 2000.

Gruntfest, E. and Handmer, J.: Dealing with flash floods: contemporary issues and future possibilities, In: Coping with Flash Floods, Edited by: Gruntfest, E. and Handmer, J., Kluwer Academic Publishers, Dordrecht, 3-10, 2001.

Ittelson, W. H., Proshansky, H. M., Rivlin, L. G., Winkel, G. H., and Dempsey, D.: An Introduction to Environmental Psychology, New York, Holt, 1974
Kates, R.: Experiencing the Environment as Hazard, In: Environmental Psychology, Edited by: Proshansky, H. M., Ittelson, W. H., and Rivlin, L. G., New York, Holt, 401-418, 1976.

Kelsch, M., Caporali, E., and Lanza, L. G.: Hydrometeorology of flash floods. In: Coping with Flash Floods, Edited by: Gruntfest, E. and Handmer, J., Kluwer Academic Publishers, Dordrecht, 19-35, 2001.

McAndrew, F. T.: Environmental Psychology, Pacific Grove, Brooks/Cole, 1993.

Montz, B. E. and Gruntfest, E.: Flash flood mitigation: recommendations for research and applications, Global Environmental Change Part B: Environmental Hazards, 4, 1, 1-22, 2002.

Polajnar, J.: Visoke vode v Sloveniji leta 1998 (High Waters in Slovenia in 1998), Ujma, Administration of the Republic of Slovenia for Civil Protection and Disaster Relief, Ljubljana, 13, 143-150, 1999.

Polic, M. and Ušenicnik, B.: Zavarovanje in nesrece (Insurance and disaster), Ujma, Administration of the Republic of Slovenia for Civil Protection and Disaster Relief, Ljubljana, 3, 93—95, 1989.

Polic, M., Rajh, S., and Ušenicnik B.: Dogajanje med poplavami leta $1990 \mathrm{v}$ oceh prizadetih prebivalcev (Events during 1990 floods in the eyes of affected inhabitants), Ujma, Administration of the Republic of Slovenia for Civil Protection and Disaster Relief, Ljubljana, 5, 114-120, 1991.

Polic, M., Brilly, M., and Tušak, M.: Influence of the living site on the perception of flood risk, Acta hydrotehnica, University of Ljubljana - FGG, Ljubljana, 16/23, 85-94, 1998.

Polic, M., Kline, M., and Zabukovec, V.: Javnost in nesrece (Public and Disasters), Znastveni Inštitut filozofske fakultete (Institute of Science Faculty of Arts), Ljubljana, 16/23, 85-94, 1998.

Whyte, A. V. T.: From Hazard Perception to Human Ecology, In: Geography, Resources, and Environment, Edited by: Kates, R. W. and Burton, I., Chicago, University of Chicago Press, 2, 1986. 